UDC 621.316.93

DOI: $10.15587 / 2706-5448.2021 .232821$

Article type «Reports on Research Projects»

\section{Yevgeniy Trotsenko, Mandar Madhukar Dixit, Volodymyr Brzhezitsky, Yaroslav Haran}

\title{
ESTIMATION OF VOLTAGE WAVEFORM AT TOP OF TRANSMISSION LINE TOWER STRUCK BY LIGHTNING OF NEGATIVE AND POSITIVE POLARITY
}

The object of research is a circuit that simulates a lightning strike to a tower of $220 \mathrm{kV}$ power transmission line, taking into consideration the reflection of a current wave from 10 nearest towers. Computation of the voltage arising at the top of the struck tower is necessary further to determine the lightning performance of transmission line by various methods. The lightning current has several maxima, in the case of a positive impulse polarity and, accordingly, several minima, in the case of a negative polarity, which are generally being called peaks. In addition, the lightning current impulse has a non-constant steepness in the entire area of current rise up to the first peak. The approximation of the real lightning current by simplified mathematical expressions cannot take into account all its real features. For a more detailed study of transient processes caused by thunderstorm activity, there is a need to use oscillograms of real lightning currents when modeling.

The problem of determining the voltage at the top of the stricken transmission line tower was solved using circuit simulation. For an in-depth study of how the shape of the lightning current impulse affects the shape of the voltage at the top of the tower struck, digitized oscillograms of real lightning currents were used. The simulation was carried out for 7 negative lightning impulses with the first peak varying from $-33.380 \mathrm{kA}$ to $-74.188 \mathrm{kA}$. In the case of positive lightning, 3 oscillograms were used with the first peak varying from $+38.461 \mathrm{kA}$ to $+41.012 \mathrm{kA}$.

The article shows that the shape of the front of the lightning current impulse and the amplitude of the first peak of the lightning current have a decisive effect on the maximum voltage value at the top of a power transmission line tower struck by lightning. The maximum voltage occurs precisely at the front of the current wave before the first peak of the lightning current. Therefore, the back flashover of the insulation from the tower to the phase conductor is most likely at a moment in time at the front of the current wave. By the time the maximum current is reached, the voltage at the top of the tower will be reduced by several tens of percent, compared to the maximum voltage at the tower, which occurs much earlier at the front of the current wave.

The conducted research contributes to the development of methods for calculating the lightning performance of power lines and extends the scope of application of circuit simulation programs.

Keywords: lightning flash, lightning performance, power line, wave reflection, oscillograms of real lightning currents.

\section{How to cite}

Trotsenko, Y., Dixit, M. M., Brzhezitsky, V., Haran, Y. (2021). Estimation of voltage waveform at top of transmission line tower struck by lightning of negative and positive polarity. Technology Audit and Production Reserves, 3 (1 (59)), 34-39. doi: http://doi.org/10.15587/2706-5448.2021.232821

\section{Introduction}

Overhead power lines rise above the earth's surface to a height of several tens of meters. Therefore, among all energy facilities, overhead power lines are most often struck by lightning. The impact of lightning on power transmission lines is the occurrence of lightning overvoltages caused by direct lightning strikes into the line and induced overvoltages caused by lightning strikes to the ground near the line. Using the terms of the theory of probability, it is possible to say that any strike of the line by lightning leads to the appearance of one of two events: disconnection of the line (failure) due to overlapping of the insulation and the absence of disconnection of the line (success). Determination of these probabilities is one of the goals of calculating the lightning performance of a power transmission line. To do this, it is necessary to know what voltage can occur on the elements of the power transmission line due to being struck by lightning. An important case of damage to a power transmission line is a direct lightning strike to the top of a power transmission tower, which is considered in this paper.

In normal operation, the potential of the power transmission tower can be assumed to be zero. Accordingly, the voltage that is applied to the string of insulators is equal to the potential difference across the traverse and the phase conductor and is equal to the operating voltage of the power line. In the case of a direct lightning strike 
to a tower or to a lightning shield wire near it, the voltage on the affected tower increases from zero to unsafe values. The back flashover of the insulation from the tower to the phase conductor will occur if the voltage across the insulator string exceeds its impulse strength. The voltage across the string of insulators increases until it intersects with the voltage-time characteristic of the insulation on the tower. The time of intersection of these two curves is used to determine the lightning current at which the insulator string will overlap. In most cases, in such problems, the lightning current injected into the tower is approximated by simplified expressions. It can be a simplified current pulse with a linear ramp front [1, 2]. The approximation of the lightning current impulse by various exponential functions can also be used [3, 4]. In addition, an approximation of the lightning current by a pulse with a forward concave front can be used [5, 6]. For an engineering assessment of the lightning current at which back flashover of insulation occurs, such simplifications may be sufficient. However, for a deep study of the transient process at the top of a tower struck by lightning, functional dependencies are needed that most closely correspond to real lightning currents.

Experimental measurements of lightning currents on special towers [7], as well as in power systems [8, 9] convincingly show that the shape of the real lightning current is very different from the simplified expressions used to describe them. In addition, the shape of the lightning current of negative and positive polarity is significantly different from each other. Therefore, works aimed at using oscillograms of real lightning currents in the problems of lightning protection of overhead power transmission lines $[10,11]$ are relevant.

Thus, the object of research is a scheme that simulates a lightning strike to a $220 \mathrm{kV}$ power transmission line tower, taking into account the reflection of the current wave from 10 nearest towers. For an in-depth study of how the shape of the lightning current impulse affects the shape of the voltage at the top of the tower struck, digitized oscillograms of real lightning currents were used. And the aim of research is to study and compare how the shape of the lightning current pulse of negative and positive polarity affects the voltage curve at the top of the affected tower using digitized oscillograms of real lightning currents.

\section{Methods of research}

This work is a continuation of the research given in [11]. For the study, a conventional $220 \mathrm{kV}$ power transmission line was selected on double-circuit towers with one lightning shield wire [12]. A sketch of a fragment of a power line route is shown in Fig. 1.

For circuit simulation of a lightning strike to a transmission line tower, a scheme was used that takes into account the reflection of current waves from adjacent transmission line towers [11]. The increase in voltage at the top of the struck tower in the first moments of a lightning discharge is determined by the surge impedance of the tower and the surge impedance of the lightning shield wire. Therefore, in the equivalent circuit, both lightning shield wires and power transmission line towers are represented by models of long lines with certain wave impedances. This circuit is shown in Fig. 2.

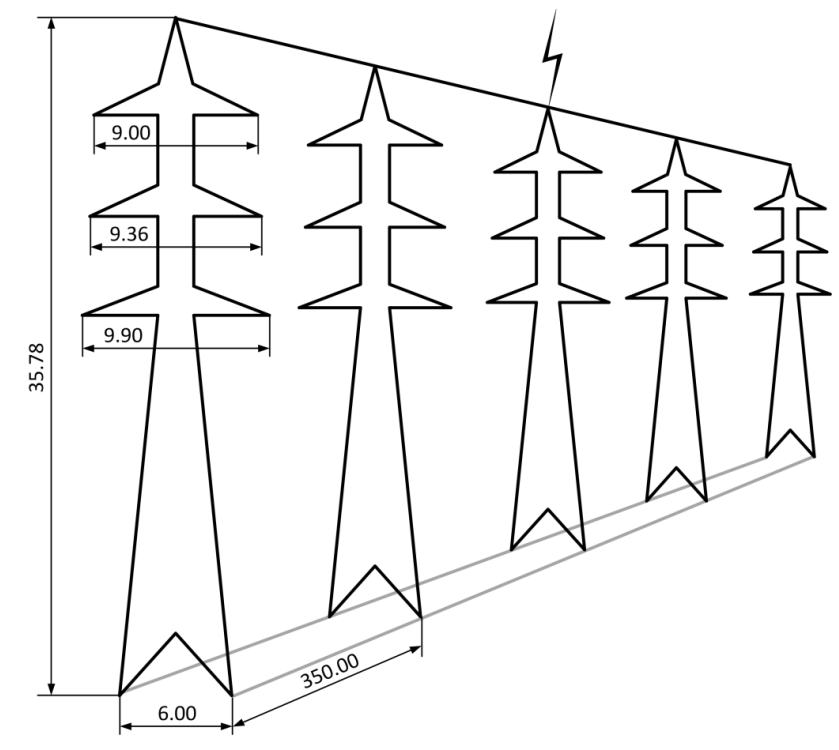

Fig. 1. Structural diagram of a lightning strike to the top of a $220 \mathrm{kV}$ power line tower

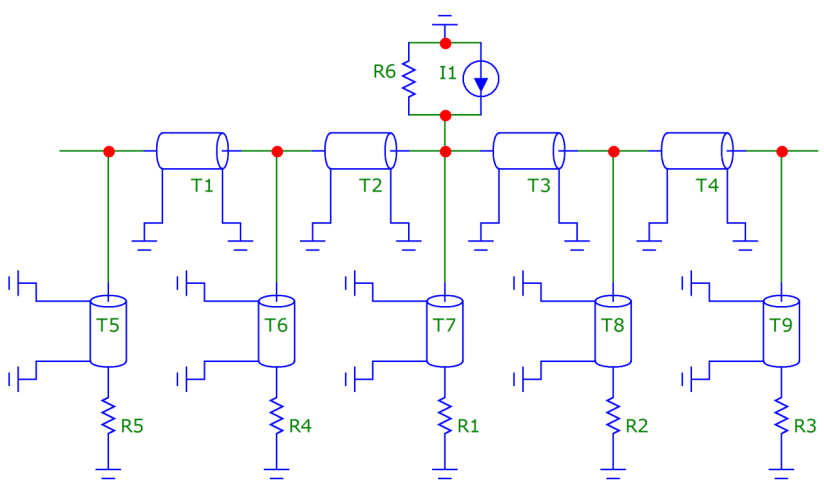

Fig. 2. Schematic modeling of a lightning strike to a power line tower, taking into account the reflection of electromagnetic waves from neighboring towers

In Fig. 2, $T_{1}-T_{4}-$ long lines simulating lightning shield wires; $T_{5}-T_{9}-$ long lines simulating transmission towers; $R_{1}-R_{5}$ - tower grounding resistance; $R_{6}$ - equivalent surge impedance of the lightning discharge channel; $I_{1}$ - lightning current source.

Simulation of the electrical circuit in Fig. 2 was performed using the Micro-Cap 12 circuit simulation program [13]. The simulation used the same parameters as in [11]. The surge impedance of the transmission line support is taken to be $169.7 \mathrm{Ohm}$, the surge impedance of the lightning shield wire is taken to be $500 \mathrm{Ohm}$, the surge impedance of the lightning discharge channel is taken to be $400 \mathrm{Ohm}$. The grounding resistance of each support was assumed to be $20 \mathrm{Ohms}$. The study consisted of injecting into the circuit in Fig. 2 lightning currents of negative and positive polarity and determination of the voltage at the top of the affected tower. To describe the shape of the lightning current, digitized oscillograms of real lightning currents obtained by Berger in 1967 and published in [7] were used. This fundamental work made a great contribution to the development of lightning research and is known to researchers all over the world. The advantage of oscillograms [7] is that they show in detail the region of the front of the lightning current pulses. Oscillograms of lightning currents were digitized and 
converted into an array of points using the free software WebPlotDigitizer 4 [14]. The results of circuit simulation are shown in the next section.

\section{Research results and discussion}

In each illustration below, the lightning current curve (blue) and the voltage curve at the top of the tower (red), due to the flow of the specified current, are aligned on the same coordinate plane. All results were obtained using the circuit in Fig. 2.

The lightning current has several maxima, in the case of a positive impulse polarity and, accordingly, several minima, in the case of a negative polarity, which are collectively called peaks. In this case, the largest peak is called directly the peak, and the rest (smaller ones) are called, respectively, the first peak, the second peak, etc. [9].

Lightning current impulse in Fig. 3 has an inconsistent steepness in the entire region of current rise up to the first peak, which is $-40.909 \mathrm{kA}$. The largest voltage peak $-789.551 \mathrm{kV}$ corresponds to the region of the front of the current pulse at the moment of its steepness decrease. Then there is a slight increase in the current steepness and at this moment (before the first current peak) the next voltage surge occurs with a smaller peak of $-718.506 \mathrm{kV}$. By the time the maximum current peak of $-47.934 \mathrm{kA}$ is reached, the voltage at the top of the tower will have time to decrease by $39.2 \%$ to $-479.852 \mathrm{kV}$.

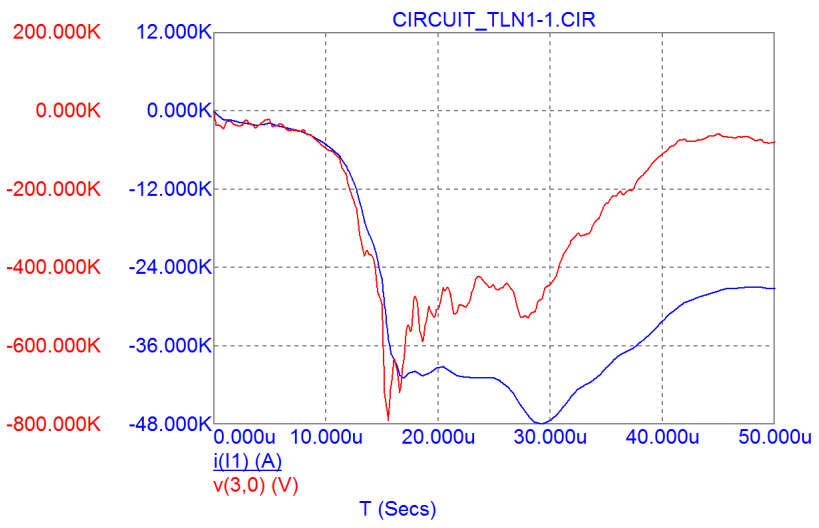

Fig. 3. Impulse of negative lightning current with the largest peak $-47.934 \mathrm{kA}$ and the voltage at the top of the tower, which it causes

Except for some peculiarities, at currents in Fig. 4, 5, the nature of the voltage at the top of the tower is similar.

Lightning current pulses in Fig. 4, 5 also have an inconsistent steepness in the entire area of current rise up to the first peak. The largest voltage peak in both cases occurs at a time point corresponding to a decrease in the lightning current steepness. Then, in both graphs, there is again a slight increase in the current steepness, and at this moment the next voltage surge occurs with a smaller peak.

In Fig. 4, the largest voltage peak is $-987.499 \mathrm{kV}$, followed by the next voltage surge with a peak value of $-968.610 \mathrm{kV}$ before the first current peak $(-55.277 \mathrm{kA})$. The maximum current on the oscillogram is located far after the front of the pulse, and in Fig. 4 is not shown. By the time the third current peak $(21.811 \mu \mathrm{s})$ is reached, the voltage at the top of the tower will have time to decrease by $38.5 \%$ to $-607.071 \mathrm{kV}$, which in percentage terms practically coincides with the previous case.

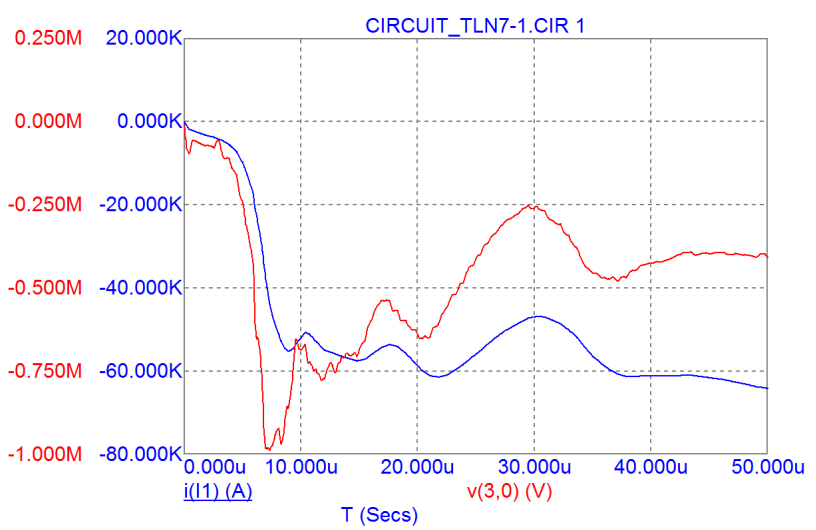

Fig. 4. Impulse of negative lightning current with the first peak $-55.277 \mathrm{kA}$ and the voltage at the top of the tower, which it causes

In Fig. 5, the largest voltage peak is $-1.125 \mathrm{MV}$ and occurs at the moment when the lightning current steepness decreases sharply. Then the current rises again with a lower steepness. The next voltage peak is $-1.089 \mathrm{MV}$ and occurs before the current maximum when the steepness of the current decreases again. In Fig. 5, the first peak of the lightning current is also the largest peak and is $-74.188 \mathrm{kA}$. Therefore, by the time the maximum current is reached $(16.293 \mu \mathrm{s})$, the voltage at the top of the tower will have time to decrease only by $19.1 \%$ to $-909.703 \mathrm{kV}$.

In Fig. 6, the largest voltage peak is $-704.146 \mathrm{kV}$, which occurs at the moment before the first peak of the lightning current $-33.380 \mathrm{kA}$.

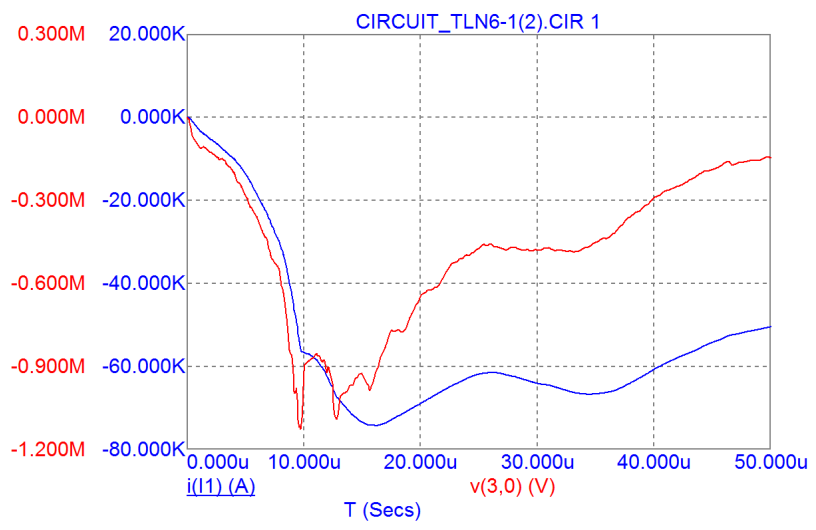

Fig. 5. Impulse of negative lightning current with the largest peak $-74.188 \mathrm{kA}$ and the voltage at the top of the tower, which it causes

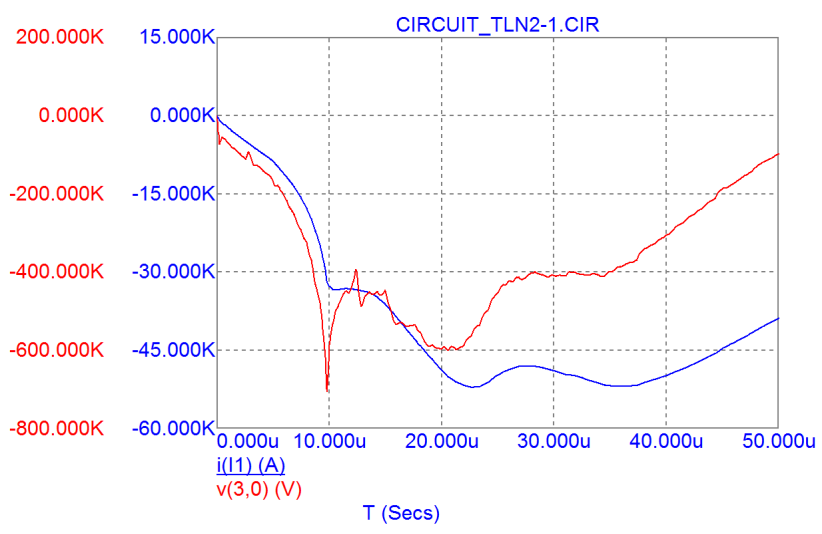

Fig. 6. Impulse of negative lightning current with the largest peak $-52.071 \mathrm{kA}$ and the voltage at the top of the tower, which it causes 
Further, the current slowly increases to a maximum with an almost unchanged steepness. For these reasons, and also due to reflections of the current wave from other towers, the next voltage peak is weakly expressed. Its value is $-599.934 \mathrm{kV}$. By the time the current maximum (22.667 $\mu \mathrm{s})$ is reached, the voltage at the top of the tower will have time to decrease only by $20.1 \%$ to $-562.570 \mathrm{kV}$.

In Fig. 7, the largest voltage peak is $-794.883 \mathrm{kV}$, which occurs at the moment before the first peak of the lightning current $-39.222 \mathrm{kA}$. Let's designate the value of the first peak of the lightning current $I_{1}$. In the section $(0.3-0.9) \cdot I_{1}$, the lightning current steepness in Fig. 7 can be considered unchanged. After the first peak, this lightning current has several more peaks, but they occur without sharp jumps. Therefore, by the time the maximum current is reached $(37.676 \mu \mathrm{s})$, the voltage at the top of the tower will have time to significantly decrease by $51.9 \%$ to $-382.111 \mathrm{kV}$.

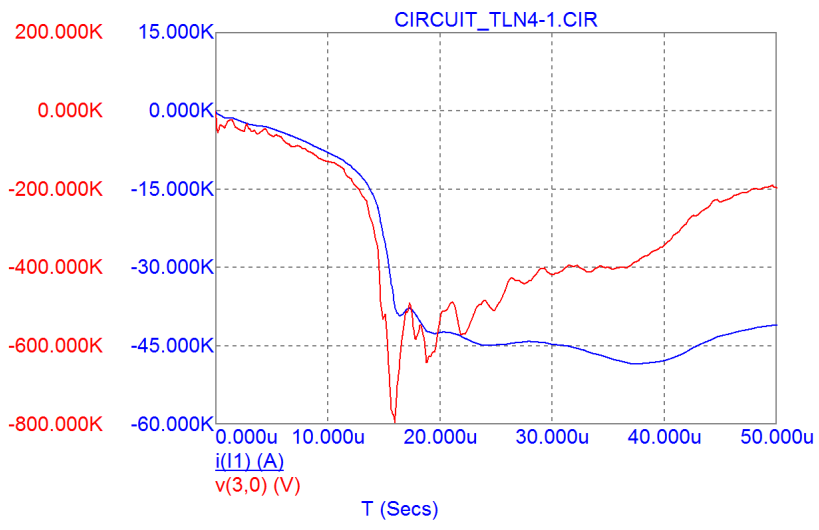

Fig. 7. Impulse of negative lightning current with the largest peak $-48.399 \mathrm{kA}$ and the voltage at the top of the tower, which it causes

In Fig. 8, the largest voltage peak is $-900.179 \mathrm{kV}$, which occurs at the moment before the first peak of the lightning current $-48.956 \mathrm{kA}$. As in the previous case, in the section $(0.3-0.9) \cdot I_{1}$, the lightning current steepness in Fig. 8 can be considered unchanged. After the first peak, this lightning current has several more peaks, the last of which is the largest and is accompanied by a relatively rapid increase in the current. Therefore, by the time the maximum current is reached $(26.972 \mu \mathrm{s})$, the voltage at the top of the tower after a certain decrease again increases to $-654.841 \mathrm{kV}$, which is $-27.3 \%$ less than the largest peak.

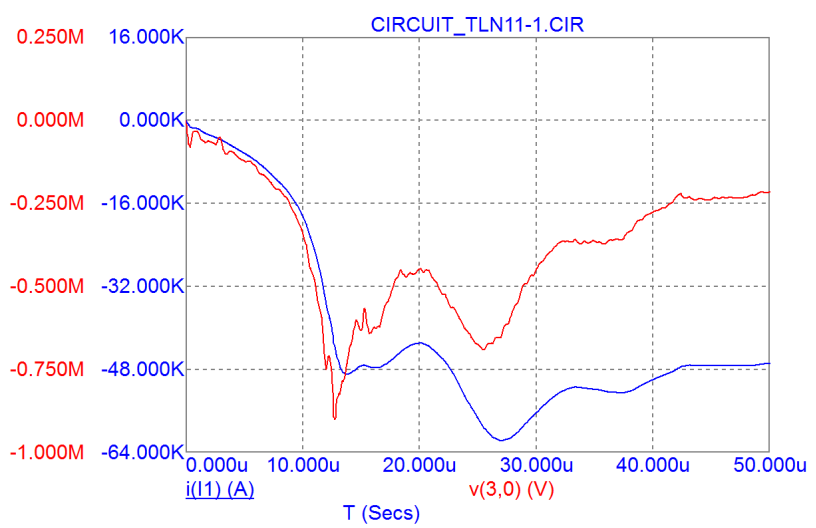

Fig. 8. Impulse of negative lightning current with the largest peak $-61.755 \mathrm{kA}$ and the voltage at the top of the tower, which it causes
As in the last two cases, in the section $(0.3-0.9) \cdot I_{1}$, the lightning current steepness in Fig. 9 can be considered unchanged.

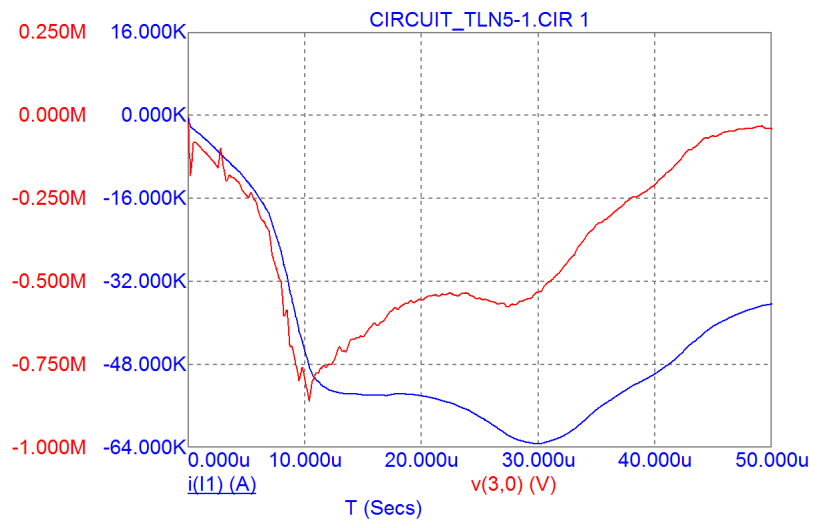

Fig. 9. Impulse of negative lightning current with the largest peak $-63.187 \mathrm{kA}$ and the voltage at the top of the tower, which it causes

In Fig. 9, the highest voltage peak is $-859.240 \mathrm{kV}$, which occurs at the moment before the first peak of the lightning current $-53.968 \mathrm{kA}$. The first current peak is very weakly expressed, in fact, it is the smallest point on an almost horizontal area, with a duration of about $7 \mu$ s, after which the current rises relatively slowly to its peak value $-63.187 \mathrm{kA}$. By the time the current maximum $(30.270 \mu \mathrm{s})$ is reached, the voltage at the top of the tower will have time to significantly decrease by $38.3 \%$ to $-529.736 \mathrm{kV}$.

Positive lightning currents have a longer rise time to the first peak and, accordingly, a lower steepness than negative lightning currents, as can be seen in the illustrations below.

In the section $(0.3-0.9) \cdot I_{1}$, the lightning current steepness in Fig. 10 can be considered unchanged. In Fig. 10, the largest voltage peak is $+428.884 \mathrm{kV}$, which occurs at the moment before the first lightning current peak of $+38.892 \mathrm{kA}$. Since this positive current rises relatively slowly, the voltage that occurs at the top of the tower is not great. For comparison, with a fast negative lightning current (Fig. 8) with almost the same first peak $(-39.222 \mathrm{kA})$, the voltage peak at the top of the tower reaches $-900.179 \mathrm{kV}$, which is 2.099 times more than in Fig. 10.

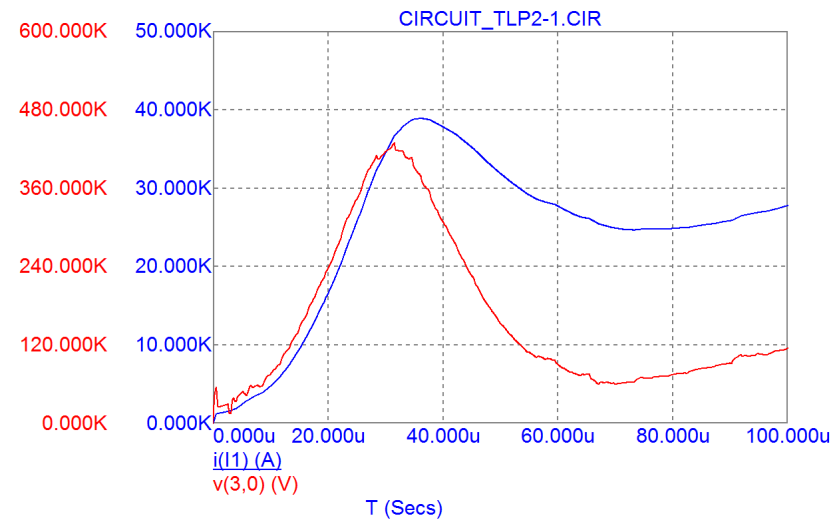

Fig. 10. Impulse of positive lightning current with the first peak $+38.892 \mathrm{kA}$ and the voltage at the top of the tower, which it causes

The front of the lightning current pulse in Fig. 11, as well as the current in Fig. 12 is characterized by inconsistent 
steepness, which causes several voltage peaks at the top of the affected tower. However, due to the fact that the currents rise to a maximum slowly, the potential at the top of the affected tower does not reach large values.

In Fig. 11, the highest voltage peak at the top of the tower is observed near the maximum current and reaches $+441.717 \mathrm{kV}$.

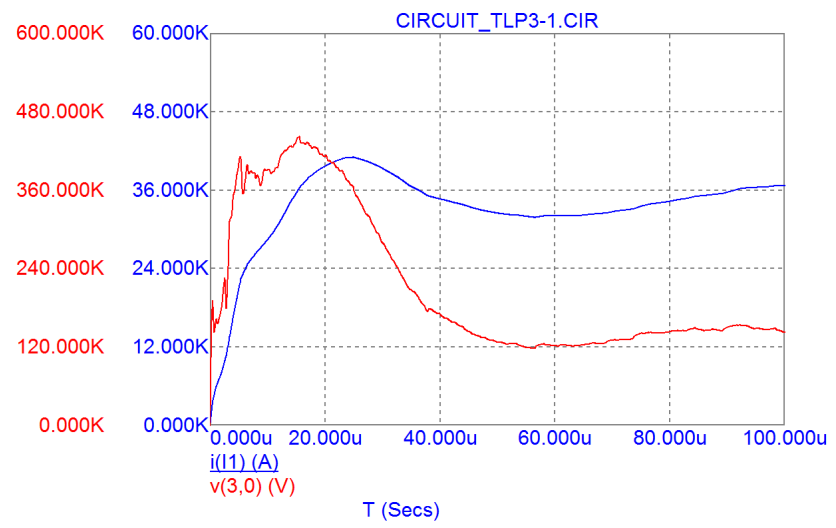

Fig. 11. Current impulse of positive lightning with the first peak $+41.012 \mathrm{kA}$ and the voltage at the top of the tower, which it causes

In Fig. 12, the highest voltage peak at the top of the tower is $+329.900 \mathrm{kV}$. This value is observed not near the maximum of the current, but earlier at the moment of the change in the rate of rise of the lightning current.

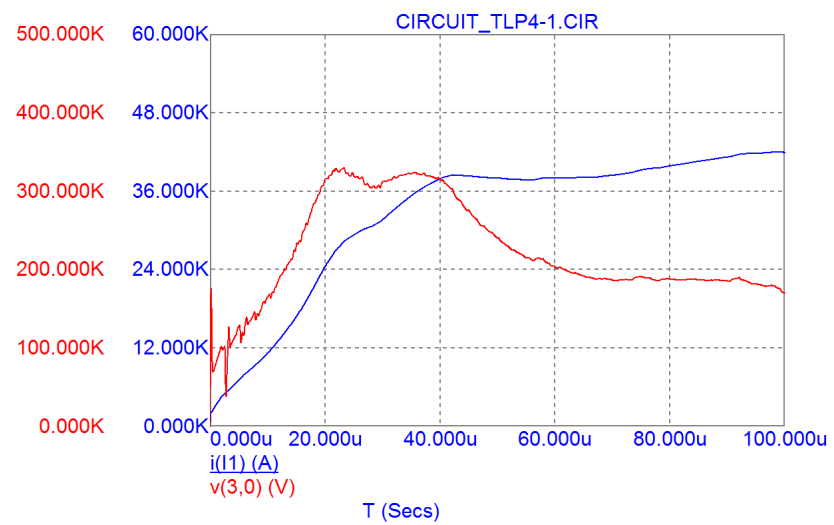

Fig. 12. Current impulse of positive lightning with the first peak

$+38.461 \mathrm{kA}$ and the voltage at the top of the tower, which it causes

In Fig. 11, the first current peak is $41.012 \mathrm{kA}$. In turn, in Fig. 12, the first current peak is $+38.461 \mathrm{kA}$.

Despite the fact that currents of positive lightning lead to lower voltage values at the top of the tower struck than currents of negative lightning, this does not mean that they are less dangerous. Positive lightning currents have a longer flow time with a value greater than half of the maximum current, and, accordingly, carry more charge than negative currents.

When calculating lightning surges arising on overhead power lines, the question often arises: how many towers should be taken into account? According to a review of publications [15] on this topic, it is necessary to take into account from 4 to 7 power transmission towers. To clarify the answer to this question using digitized oscillograms of real lightning currents, studies were carried out, the results of which are shown in Table 1.
Maximum voltage at the top of the tower struck depending on the number of adjacent towers at a current of negative and positive lightning

\begin{tabular}{|c|c|c|c|c|c|}
\hline \multirow{2}{*}{$\begin{array}{c}\text { Lightning } \\
\text { current }\end{array}$} & \multicolumn{5}{|c|}{$\begin{array}{r}\text { Maximum voltage }(\mathrm{kV}) \text { at the top of the affected support, } \\
\text { depending on the number of adjacent supports }\end{array}$} \\
\cline { 2 - 6 } & 2 supports & 4 supports & 6 supports & 8 supports & 10 supports \\
\hline Fig. 3 & -794.087 & -790.247 & -789.347 & -789.970 & -789.551 \\
\hline Fig. 4 & -989.672 & -987.455 & -987.500 & -987.499 & -987.499 \\
\hline Fig. 5 & -1127 & -1124 & -1125 & -1125 & -1125 \\
\hline Fig. 6 & -705.215 & -704.178 & -703.191 & -704.142 & -704.146 \\
\hline Fig. 7 & -796.655 & -794.997 & -794.072 & -794.928 & -794.883 \\
\hline Fig. 8 & -903.372 & -899.930 & -899.853 & -900.257 & -900.179 \\
\hline Fig. 9 & -864.122 & -860.304 & -859.475 & -859.208 & -859.240 \\
\hline Fig. 10 & +440.387 & +429.688 & +429.225 & +428.553 & +428.884 \\
\hline Fig. 11 & +448.707 & +441.733 & +442.274 & +441.979 & +441.717 \\
\hline Fig. 12 & +347.464 & +330.796 & +332.000 & +331.246 & +329.900 \\
\hline
\end{tabular}

These results show how the maximum voltage at the top of the affected tower changes, if, in addition to it, in the circuit in Fig. 2 also includes 2, 4, 6, 8 or 10 towers. These numbers indicate the total number of towers located on either side of the affected tower.

According to the Table 1, at currents of negative lightning, it is recommended, in addition to the affected tower, to take into account the reflection from at least 6 other power transmission towers. Since the duration of positive lightning is usually longer than that of negative lightning, this makes it necessary to take into account the reflection of more adjacent transmission towers. Therefore, according to Table 1 for positive lightning currents, it is recommended, in addition to the affected tower, to take into account the reflection from at least 8 other transmission line towers. Then, the single minimum value for lightning of both polarities can be considered 8 transmission line towers (in addition to the affected tower).

\section{Conclusions}

During the work, the oscillograms of real currents of negative and positive lightning, recorded by Berger on Monte San Salvatore mountain in 1967, were digitized and converted into an array of points. The simulation and visualization of the voltage arising at the top of a double-circuit tower of a $220 \mathrm{kV}$ power transmission line in the event of being struck by lightning, the current of which is determined by a digitized oscillogram of a real lightning, has been carried out. As a result of the experiment, it was shown that the shape of the front of the lightning current pulse and the amplitude of the first peak of the lightning current have a decisive significance for the maximum voltage value at the top of the power transmission line tower struck by lightning. The maximum voltage occurs precisely at the front of the current wave before the first peak of the lightning current. Therefore, the back flashover of the insulation from the tower to the phase conductor is most likely at a moment in time at the front of the current wave. The simulation was carried out for 7 negative lightning impulses with the first peak varying from $-33.380 \mathrm{kA}$ to $-74.188 \mathrm{kA}$. In the case of positive lightning, 3 oscillograms were used with 
the first peak varying from $+38.461 \mathrm{kA}$ to $+41.012 \mathrm{kA}$. By the time the maximum current is reached, the voltage at the top of the tower will be reduced by several tens of percent, compared to the maximum voltage on the tower, which occurs much earlier at the front of the current wave. When calculating lightning overvoltage arising on overhead power lines, it is necessary to take into account the reflection of the current wave from neighboring power line towers. Lightning strike transients develop at different rates. Then, the single minimum value for lightning of both polarities can be considered 8 transmission line towers (in addition to the affected tower). The use of oscillograms of real lightning currents improves the accuracy and clarity of the study of the effect of atmospheric overvoltage on overhead power lines.

\section{References}

1. Hashimoto, S., Baba, Y., Nagaoka, N., Ametani, A., Itamoto, N. (2010). An equivalent circuit of a transmission-line tower struck by lightning. 2010 30th International Conference on Lightning Protection (ICLP). doi: http://doi.org/10.1109/iclp.2010.7845761

2. Melo, M. O. B. C., Fonseca, L. C. A., Fontana, E., Naidu, S. R. (1997). Lightning Performance of Compact Transmission Lines. International Conference on Power Systems Transients (IPST'97). Seattle, 319-324.

3. Mohajeryami, S., Doostan, M. (2016). Including surge arresters in the lightning performance analysis of $132 \mathrm{kV}$ transmission line. 2016 IEEE/PES Transmission and Distribution Conference and Exposition (TESD). doi: http://doi.org/10.1109/tdc.2016.7519906

4. Fekete, K., Nikolovski, S., Knezevic, G., Stojkov, M., Kovac, Z. (2010). Simulation of lightning transients on $110 \mathrm{kV}$ overheadcable transmission line using ATP-EMTP. Melecon $2010_{-}^{-}$ 2010 15th IEEE Mediterranean Electrotechnical Conference. doi: http://doi.org/10.1109/melcon.2010.5475950

5. Kizilcay, M., Neumann, C. (2007). Backflashover Analysis for $110-\mathrm{kV}$ Lines at Multi-Circuit Overhead Line Towers. International Conference on Power Systems Transients (IPST'07), 1-6.

6. Asif, M., Lee, H.-Y., Park, K.-H., Shakeel, A., Lee, B.-W. (2019) Assessment of Overvoltage and Insulation Coordination in Mixed HVDC Transmission Lines Exposed to Lightning Strikes. Energies, 12 (21), 4217. doi: http://doi.org/10.3390/en12214217

7. Berger, K. (1967). Novel observations on lightning discharges: Results of research on Mount San Salvatore. Journal of the Franklin Institute, 283 (6), 478-525. doi: http://doi.org/10.1016/00160032(67)90598-4

8. Barker, P. P., Mancao, R. T., Kvaltine, D. J., Parrish, D. E. (1993). Characteristics of lightning surges measured at metal oxide distribution arresters. IEEE Transactions on Power Delivery, 8 (1), 301-310. doi: http://doi.org/10.1109/61.180350
9. Narita, T., Yamada, T., Mochizuki, A., Zaima, E., Ishii, M. (2000). Observation of current waveshapes of lightning strokes on transmission towers. IEEE Transactions on Power Delivery, 15 (1), 429-435. doi: http://doi.org/10.1109/61.847285

10. Trotsenko, Y., Brzhezitsky, V., Mykhailenko, V. (2020). Estimation of Discharge Current Sharing Between Surge Arresters with Different Protective Characteristics Connected in Parallel. 2020 IEEE 7th International Conference on Energy Smart Systems (ESS). Kyiv, 73-78. doi: http://doi.org/10.1109/ ess50319.2020.9160296

11. Trotsenko, Y., Dixit, M. M., Brzhezitsky, V., Haran, Y. (2021). Alternative evaluation of voltage at top of transmission line tower stricken by lightning. Technology Audit and Production Reserves, 2 (1 (58)), 33-39. doi: http://doi.org/10.15587/ 2706-5448.2021.228659

12. Halkude, S. A., Ankad, P. P. (2014). Analysis and Design of Transmission Line Tower $220 \mathrm{kV}$ : A Parametric Study. International Journal of Engineering Research \& Technology, 3 (8), 1343-1348.

13. Micro-Cap 12. Electronic Circuit Analysis Program. Reference Manual (2018). Sunnyvale: Spectrum Software, 1098. Available at: http://www.spectrum-soft.com/download/rm12.pdf

14. Rohatgi, A. (2020). WebPlotDigitizer. Version 4.4. Pacifica. Available at: https://automeris.io/WebPlotDigitizer

15. Moselhy, A. H., Abdel-Aziz, A. M., Gilany, M., Emam, A. (2020) Impact of First Tower Earthing Resistance on Fast Front BackFlashover in a $66 \mathrm{kV}$ Transmission System. Energies, 13 (18), 4663. doi: http://doi.org/10.3390/en13184663

Yevgeniy Trotsenko, PhD, Associate Professor, Department of Theoretical Electrical Engineering, National Technical University of Ukraine «Igor Sikorsky Kyiv Polytechnic Institute», Kyiv, Ukraine, e-mail: y.trotsenko@kpi.ua, ORCID: https://orcid.org/0000-00019379-0061

Mandar Madhukar Dixit, Assistant Professor, Department of Electrical Engineering, Vishwaniketan Institute of Management Entrepreneurship and Engineering Technology, Khalapur, Maharashtra, India, e-mail: mmdixit@vishwaniketan.edu.in, ORCID: https://orcid.org/ 0000-0003-1959-7815

Volodymyr Brzhezitsky, Doctor of Technical Sciences, Professor Department of Theoretical Electrical Engineering, National Technical University of Ukraine «Igor Sikorsky Kyiv Polytechnic Institute», Kyiv, Ukraine, e-mail: v.brzhezitsky@kpi.ua, ORCID: https://orcid.org/ 0000-0002-9768-7544

Yaroslav Haran, PhD, Assistant, Department of Theoretical Electrical Engineering, National Technical University of Ukraine «Igor Sikorsky Kyiv Polytechnic Institute», Kyiv, Ukraine, e-mail: y.garan@kpi.ua, ORCID: https://orcid.org/0000-0003-3242-9218 